A LEGITIMIDADE DA INTERPRETAÇÃO

\author{
CONCRETISTA DAS NORMAS \\ CONSTITUCIONAIS FRENTE AOS \\ DIREITOS FUNDAMENTAIS
}

NILSON AFONSO DA SILVA 


\title{
A LEGITIMIDADE DA INTERPRETAÇÃO CONCRETISTA DAS NORMAS CONSTITUCIONAIS FRENTE AOS DIREI- TOS FUNDAMENTAIS
}

\author{
NILSONAFONSO DASILVA
}

\section{RESUMO}

Este artigo é a tentativa de encontrar justificativa para uma aplicação efetiva da Constituição brasileira, buscando suas razões na legitimidade do Poder Constituinte e na necessidade de dar aplicação concreta ao texto magno. Parte da noção que o direito constitucional tem primazia no ordenamento jurídico pátrio - não se olvidando que o ato de interpretar possui forte aspecto subjetivo - como medida necessária para aproximação do Estado Democrático de Direito.

\begin{abstract}
This article is an attempt of finding a justification for an effective application of the Brazilian Constitution, pursuing its reasons in the legitimacy of the Constituent Power and in the necessity of giving concrete application to the constitutional text. Part of the notion that the Constitutional Law has the primacy in the fatherland juridical ordain - not forgetting that the act of interpreting has strong subjective aspect - like necessary measure to approximation of the Democratic State of Law.
\end{abstract}

\footnotetext{
${ }^{1}$ Pós-graduando em Direito Constitucional pela Universidade do Tocantins - UNITINS, Juiz de Direito Titular da Comarca de Tocantinópolis-TO
} 


\section{INTRODUÇÃo}

Não se trata de apresentar qualquer novidade, mas da necessidade de utilizar o sistema legal de maneira efetiva na busca da implementação de melhorias para os jurisdicionados.

Com o crescimento desmedido do fator humano do Estado, é necessário implementar outro modelo de interpretação do direito, não com a proposta utópica de atingir a quimera da Justiça, mas para atender a necessidade premente de pacificação social.

Para tanto será abordado a existência do Estado como fator de acoplamento dos interesses em jogo, ou seja, da disputa de quem tem Poder de barganha, dando ênfase a massificação de parte da sociedade.

\section{BREVE NOÇÃO DE CONSTITUCIONALISMO}

A justificação para o direito nasce da necessidade de intervenção estatal como forma de amainar os conflitos de interesses individuais e coletivos, nem sempre o ser humano se satisfaz com a renuncia de interesses, sendo necessário algumas vezes a intervenção de um elemento outro que com base num conjunto normativo compõe o conflito. Esta é a razão primeira do direito.

Vale notar que foi através do conflito de interesse entre o Monarca e os barões que surgiu a noção de contenção do Poder pela Norma (João sem terra 1215).

A origem do Estado organizado é indissociável da noção de disputa pelo Poder, lembrando que o surgimento do constitucionalismo é muito anterior ao primeiro texto constitucional, devendo ser salientado que o movel das primeiras constituições escritas da era moderna (norte-americana de 1.787 e francesa 1.789), fora a contenção do Poder e a defesa dos diretos individuais, hodiernamente temos outras necessidades: solidariedade, integração, continuidade e uni- 
versalização. Portanto, a história do constitucionalismo é a tentativa de contenção de quem detém o Poder pela imposição de um sistema legal de normas. Assim, as normas constitucionais devem estar acima dos governantes, sendo recomendável a participação popular na feitura da norma como forma de legitimar o Poder. A constituição brasileira deixa isto claro em seu artigo $1^{\circ}$, parág. único, quando diz que todo Poder emana do Povo.

Indiscutivelmente o direito constitucional tem função privilegiada no conjunto de normas jurídicas, donde decorre que na sua interpretação há elementos peculiares, dentre eles a idéia de supremacia da Constituição, donde decorre a denominada interpretação conforme a Constituição, sendo indissociável ainda a noção de defesa intransigente dos direitos e garantias fundamentais.

A constituição brasileira de origem popular, fora concebida dentro de um modelo democrático de representatividade, portanto, oriundo de um Poder constituinte originário.

Vale notar que a festejada classificação da aplicabilidade da norma constitucional de José Afonso da Silva, cinge-se elaborada anteriormente ao texto de 1988 , atualmente, não atende inteiramente a melhor exegese.

Admitindo na sua inteireza esta teoria, na prática teríamos que o legislador ordinário (infraconstitucional) estaria acima do legislador constitucional originário, porquanto para esta basta quorum simples em votação única enquanto que naquela necessário dois turnos de votação em cada casa com quorum de dois terço. Assim, caso o legislador ordinário não fizesse a norma o texto constitucional nunca seria aplicada, parece um contra censo, pois o legislador infraconstitucional teria mais poder do que o próprio legislador constituinte, o que é um absurdo.

Hoje, com as novas necessidades do sistema jurídico não se pode aceitar inteiramente esta classificação, sob pena de entregar a efetividade da vontade do constituinte originário aos caprichos do legisla- 
dor ordinário que na maioria das vezes está acoplada ao arbítrio do Poder executivo.

Indiscutivelmente referida técnica de aplicabilidade das normas constitucionais, adotada por muitos doutrinadores e tribunais, inquestionavelmente é demasiadamente útil para compreensão da matéria, entretanto, é necessário ponderar, repiso, que fora concebida durante outro texto constitucional. É obvio que cada teoria pertence ao seu tempo.

Sieyès, já dizia: "A nação existe antes de tudo, ela é a origem de tudo. Sua vontade é sempre legal, ela é a própria lei". Ora, se no nosso caso temos um texto constitucional oriundo de um poder constitucional originário, não é aceitável negar algum grau de aplicabilidade a esta norma.

\section{QUEM É O INTEPRETE CONSTITUCIONAL}

É cediço que quase todas as constituições apregoam que o Poder tem origem no Povo - certo é que os detentores do Poder sempre tentam burlar este mandamento.

Todas as constituições que desejam ser perenes e democráticas necessitam do apoio popular.

Considerando que a função principal do texto constitucional é a limitação e a organização do Poder, por obvio que este texto deve ser escrito de forma clara para o conhecimento de todos os jurisdicionados, portanto, inexoravelmente toda a população indistintamente - aí inclui-se até o estrangeiro que aqui estiver - é genuinamente o interprete da constituição.

No atual estágio não se admite que somente os órgãos oficiais sejam os detentores da prerrogativa de interpretação.

Estamos numa sociedade aberta, donde os ventos democráticos sopram com freqüência, embora seja necessário ponderar que nem todas as interpretações atinjam toda a população, induvidosamente 
quando ela (população) procura o Judiciário, estará buscando a sua prerrogativa de interpretação constitucional. Não se pode olvidar que a interpretação judicial da norma esta sujeita a pressões sociais, até porque o reclame popular é quem legitima o Poder.

Desta feita, no caso do sistema judiciário constitucional pátrio, todos têm a prerrogativa de buscar a interpretação constitucional. Lembrando ainda, que interpretar é um ato subjetivo, de vontade, embora com opiniões respeitáveis em contrário como por exemplo Manoel Gonçalves Ferreira Filho.

\section{NECESSIDADE DE TORNAR O MANDAMENTO CONSTI- TUCIONAL EFETIVO}

Fácil notar no artigo 84 do CDC, texto infraconstitucional datado de 11.09.1990, a preocupação do Congresso com a necessidade de efetividade do mandamento legal, o que se percebe ainda no artigo * 461- A do CPC e na lei 11.232 de 22.12.2005, demonstrando cabalmente que o legislador ordinário tem preocupação com a efetividade da Justiça. 0 que indica a necessidade de todos os interpretes do texto constitucional também buscar a efetividade.

É necessária uma mudança de paradigma. Não se pode admitir que um texto constitucional elaborado democraticamente, se verta simplesmente em uma carta de intenções, todos os agentes devem ter preocupação com sua efetividade. Certo é que isto não ocorrera num toque de Midas, mas de maneira organizada, pois ao mesmo tempo em que se reconhece a necessidade de efetividade, há também a necessidade de segurança jurídica.

Devendo ainda ser salientado que não temos condições materiais, o Estado perfeito não existe, sendo salutar atender a teoria da reserva do possível.

Assim, ao interpretar o texto constitucional mister criar amarras entre os princípios da Carta Magna de tal ordem que os mandamentos desta não possa ser reduzido tão só a um procedimento de ordem 
política, judicial ou administrativo, mas dar conteúdo substancial à própria Constituição, pois nada há de desnecessário na Constituição Federal.

A própria Carta prevê o principio da inafastabilidade da prestação Jurisdicional, impedindo que qualquer ameaça ou lesão a direito venham a ser subtraídas do conhecimento do Poder Judiciário, pedra angular dos direitos fundamentais. Quando a própria Carta esteṇde a garantia à ameaça quis o constituinte originário ampliar as possibilidades de proteção ao próprio direito material, independente da eventual lesão, dificultando a prática de atos ilegais por qualquer ente.

\section{O ESTADO DEMOCRÁTICO DE DIREITO}

0 Estado Democrático de Direito tem previsão constitucional como princípio fundamental (art. $1^{\circ}$, caput da CF).

Vale notar que no aspecto de previsão legal, como norma constitucional, o Estado de Direito surgiu quase ao mesmo tempo que na América do Norte e Europa Ocidental, no entanto, no plano da concretização isto não ocorreu, sendo salutar observar que na maioria dos Estados democráticos houve urna evolução no aspecto material, do Estado garantista passando pelo Estado social até atingir o Estado Democrático de Direito, infelizmente, isto não ocorreu no Brasil.

Aqui apesar da normatização legal, por fatores outros não fora obtido esta evolução, sendo mister salientar como fator preponderante, a falta de compromisso dos Poderes constituídos - não se excluindo qualquer um - com o texto constitucional.

Para compreensão das relações sociais, obviamente deve ser sopesado com bastante ênfase o fator econômico, ou seja, aquilo que dá condições materiais de mudança.

Neste compasso a sociedade massificada e a economia globalizada imposta, leva a mudança de paradigma. No plano internacional, o 
princípio democrático postula a reunião de povos (não formalmente de Estados), numa organização federativa mundial, todavia, se faz necessário a criação de instituições jurídicas adequadas.

Ocorre que isto demanda correlação de forcas, e como sempre, é nitidamente desfavorável aos pobres, e, apesar de propaganda avassaladora patrocinada pelos que levam vantagens no capitalismo internacional, de que a globalização é necessária e útil, cresce em todos os povos o sentimento ético da ilegitimidade das normas e instituições que regem as relações internacionais, basta atentar para as atrocidades cometidas no Iraque, e a indiferença com o Povo Africano. Neste diapasão, nítido observar que na sociedade atual, o Estado de Direito encontra-se sob duas vertentes de pressão que limitam suas possibilidades de concretização: de um lado, a prevalência cada vez maior de uma ordem mundial, que se justifica pelo poderio econômico e técnico dos meios de produção; e por outro lado, a forte prevalência das etnias locais e fundamentalistas, principalmente no Oriente Médio.

Assim, por detrás das divergências ideológicas com a conseqiiente intensificação dos choques culturais, é possível vislumbrar dois movimentos antagônicos, que necessita de integração: o capitalismo globalizado e a construção de um sistema mundial de direitos humanos.

\section{CONCLUSÃo}

Por óbvio que interpretar a constituição também significa atualizá-la, onde o exegeta não pode permanecer inerte ao reclames sociedade.

0 simples decorrer do tempo exige nos sistemas constitucionais formais, utilizar critérios evolutivos que possam buscar no próprio texto atualizar e atender as novas necessidades da sociedade, de maneira a atender o novo quadro político e social que tem natureza dinâmica. 
Desta feita, na interpretação concretista deve o exegeta não descurar da necessidade de não dar somente atenção ao conteúdo unilateral do social, sob pena de fazer uma interpretação sem juridicidadee sem conhecimento sistêmico, transformando o Direito Constitucional numa sociologia ou numa Jurisprudência Constitucional.

0 que se deve buscar na interpretação concretista é dar ao texto legal o espírito da constituição como um todo.

É, quando a interpretação envolver direitos fundamentais, demanda ainda mais zelo, pois elas consubstanciam um núcleo de direitos que ocupam lugar privilegiado dentro da nossa Carta Magna.

Os direitos fundamentais não se esvaem em mera interpretação, sendo necessária uma concretização, donde deve ser sopesado o princípio da unidade da Constituição, para preservar o espírito constitucional do texto, buscando assim, eliminar contradições e dar unidade ao sistema.

Neste sentido é a lição de Paulo Bonavides:

"A nova hermenêutica visa concretizar o preceito constitucional, de tal maneira que concretizar é algo mais do que interpretar, e aperfeiçoar conferir sentido à norma, ou seja, é interpretar com criatividade, seguindo princípio que direcionam a atividade e preconizam a ponderação nas situações conflituosas, inclusive aquelas que envolvem problemas relativos aos direitos fundamentais. Os princípios que pela ponderação não são utilizados em plena força na solução do caso não são expurgados do sistema normativo, ao contrário, nele permanecem podendo ser utilizados em situações futuras de conflito".

Assim, este método interpretativo tem assaz vantagem na exegese dos direitos fundamentais, porque toma em consideração a realidade social evidenciada, e, como o seu rol é aberto, portanto, sujeito a modificações e permeada de normas-princípios, fácil fica a atualização do texto frente às mudanças dinâmicas da sociedade. 


\section{REFERÊNCIAS BIBLIOGRÁFICAS}

BOBBIO, Norberto, Teoria Geral do Direito, Martins Fontes, 2007. BONAVIDES, Paulo. Curso de direito constitucional. 11. ed. revista, atualizada e ampliada. São Paulo: Malheiros Editores, pag. 585.2001.

COMPARATO, Fábio Konder, Etica, Edit Cia das Letras, 2006

Emmanuel Sieyès, Qu`est-ce que Le tiers etat, apud, TAVARES, André Ramos, Curso de Direito Constitucional, 5 edição, pag. 30.2007.

FELHO, Manoel Gonçalves Ferreira Filho, Curso de Direito Constitucional, p, 378.

JÚNIOR, Fredie Didier, AÇÕES CONSTITUCIONAIS, 2 edição, edit Podivm, 2007.

NEVES, Marcelo, Entre Têmis e Leviatã: uma relação difícil, edit. Martins Fontes. 2006.

TAVARES, André Ramos, Curso de Direito Constitucional, 5 edição, pag. 30.2007. 